Investigating teachers and students' perceived importance of motivational strategies: The case of secondary schools in East Wollega, Ethiopia

\author{
Mekuria, Zewdie Bedada \\ Wollega University, Ethiopia (zmeku1995@gmail.com)
}

Received: 19 October 2018

Available Online: 14 February 2019
Revised: 16 January 2019 DOI: $10.5861 /$ ijrsll. 2019.3010

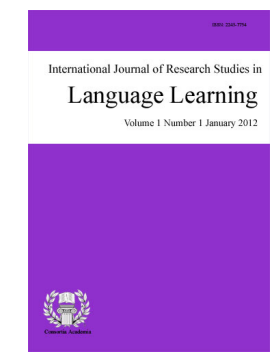

ISSN: $2243-7754$ Online ISSN: 2243-7762

\title{
Abstract
}

This study investigated secondary school English language teachers and students' perceived importance of motivational strategies, in East Wollega, Ethiopia. It utilized Dornyei's (2001) system of motivational strategies framework which was established based on the process model of L2 motivation. To achieve the purpose of the study, a survey design specifically a cross-sectional survey design was employed. 65 teachers and 177 students participated using convenience sampling and stratified purposeful sampling, respectively. To collect data, two sets of motivational strategy questionnaires, one of which for teachers and the other for students, were utilized. The findings revealed that there was a shared as well as a mismatch of perception between teacher and student participants on the importance of motivational strategies. Thus, it can be concluded that there is a gap between teacher and student participants pertaining to what promotes students' motivation to learn English. The key implication of this finding is, therefore, secondary schools English language teachers in the research setting need to develop a balanced view on the importance of motivational strategies when implementing in the classroom. Based on the conclusions made, it was suggested to replicate more studies of this kind at various EFL settings to gain a broader perspective on the perceived importance of motivational strategies in different EFL learning contexts.

Keywords: motivation; L2 motivation; motivational strategies; students' motivation 


\section{Investigating teachers and students' perceived importance of motivational strategies: The case of secondary schools in East Wollega, Ethiopia}

\section{Introduction}

Motivation has been widely considered by both teachers and researchers as one of the key factors that influence the rate and success of foreign language learning. It provides the primary impetus to initiate L2 learning and later the driving force to sustain the long and often tedious learning process (Dorney, 2005). Without sufficient motivation, Dorney added that even individuals with the most remarkable abilities cannot accomplish long-term goals of language learning. Insufficient motivation on the part of students is, therefore, one of the most challenging problems in the process of foreign language learning. In this regard, the issue of motivation seems to be of particular pertinence to Ethiopian foreign language teaching context where a plethora of research works show a general dissatisfaction in students' performance in English language at different levels of the education system (Tamene, 2000; Negash, 2006; Eshetie, 2010).

Moreover, there is a growing body of literature that motivation is a crucial factor for students to exert effort and also persist in their efforts in the process of foreign language learning (Gardner, 1985; Ellis, 1994; Dornyei \& Otto, 1998; Dornyei, 2005). To this end, enhancing students' language learning motivation has a paramount importance. This evokes the question of both how to enhance students' motivation and whose responsibility is to promote students' motivation. Pertaining to the responsibility, it is widely accepted that motivating students and keeping them motivated during the tenure of their studies rests mainly with language teachers (Dornyei, 2001, 2005; Ushioda, 2005). More specifically, Dornyei (2001) confirms that there is no doubt that students' motivation can be consciously enhanced by using motivational strategies. Therefore, it can be recognized that teachers have the power to promote students' language learning motivation using various motivational strategies. However, the nature of L2 motivation researches conducted so far are not helpful for language teachers to use motivational strategies in the classroom. This is because most of the studies that investigated L2 motivation over the past 50 years were more concerned with analyzing various motives and validating motivational theories rather than finding practical ways to motivate language learners (Dornyei \& Otto, 1998; Cheng \& Dornyei, 2007).

In fact, cognizant of the importance of teacher's use of motivational strategies to promote students' language learning motivation, motivational strategies research has recently gained significance. In connection with this, Cheng and Dornyei (2007) explain that as the lack of motivation may cause disappointing learning outcomes, the need remains to look for some specific motivational strategies in order to integrate motivation in the language learning process. Accordingly, a number of motivational strategies studies have been conducted worldwide. The studies include Cheng and Dornyei (2007) in Taiwan; Alrabai (2011) in Saudi Arabia; Ruesch, Bown, and Dewey (2012) in the United States of America, and Astuti (2013) in Indonesia and many others.

The findings of the above studies commonly revealed that motivational strategies are culture dependent, and that there is no universal motivational strategy that can be applied to all foreign language classrooms across all cultures. In fact, the contextual realities of different learning environments such as learning resources, teaching materials, and the culture of the society may affect teachers and students' perception of motivational strategies and its actual implementation. Hence, motivational strategies which are effective in one context of teaching and learning process may not work at all in a different context. This implies that as the effectiveness of motivational strategies show variation in different EFL contexts, it is still an area that needs further investigation in different foreign language teaching contexts. Despite this fact, to the current researcher's best knowledge, there is a dearth of motivational strategies studies in Ethiopian foreign language teaching context. This could result a lack of sufficient attention given to the fundamental role that motivational strategies play in Ethiopian foreign language teaching context. 
In this study, therefore, an attempted was made to investigate teachers and students' perceived importance of motivational strategies in promoting students' English language learning motivation. The current researcher investigated both teachers and students because of his intention to get a balanced view regarding the importance of motivational strategies. In this regard, Smith (2016) explicates that motivational strategy is not considered motivating only because a teacher perceived it important and implemented it during a lesson. This implies that to motivate students more effectively, investigating students' sentiment toward motivational strategies is also crucial. In this study, therefore, the following specific research questions were posited to be answered.

$>\quad$ Which macro and micro motivational strategies do teachers perceive as most important for enhancing students' motivation?

$>\quad$ Which macro and micro motivational strategies do students perceive as most important for enhancing their language learning motivation?

$>$ What are the top 15 micro motivational strategies that teacher and student participants perceive as most important for enhancing students' motivation?

In this study, macro motivational strategy refers to general motivational guideline that aims at orienting the teacher on how to introduce a more motivation-sensitive teaching practice (Dornyei, 2001). On the other hand, micro motivational strategies refer to specific individual motivational techniques and practices by which human achievement behavior can be promoted (Ibid). Each macro motivational strategy is, therefore, made up of a set of interrelated micro motivational strategies.

\section{Review of Related Literature}

\subsection{Conceptualizations of L2 Motivation}

Motivation is one of the most prolific research areas in the field of second language acquisition (SLA). Nonetheless, whereas a lot of research discussions have centered upon the notion of motivation with in language learning, it has become apparent that there is no consensus on conceptualizing it. Consequently, various definitions of motivation have been forwarded in L2 learning over time. To begin with, Gardner (1985, p. 10) defined it as "the combination of effort plus desire to achieve the goal of learning the language plus favorable attitudes towards learning a new language". Three components constitute Gardner's definition of L2 motivation: (a) making an effort to achieve a goal, (b) the desire to achieve a goal, and (c) positive attitude towards learning the target language. Ellis (1994), excluding the concept of favorable attitudes towards learning a new language from Gardner's definition, defined that "L2 motivation refers to the effort that learners put into learning the L2 as a result of their need or desire to learn it" (p. 509). From these definitions, therefore, it can be discerned that L2 motivation is the extent to which the individual strives to learn the new language as a result of a desire to achieve the goal of language learning plus the individual's attitude towards learning the target language.

On the other hand, in the contemporary view of L2 motivation, although the previous scholars views are not neglected, L2 motivation is recognized as a dynamic process that fluctuates overtime because of a number of factors or reasons. In line with this idea, Dornyei and Otto (1998, p. 64) defined L2 motivation as the " dynamically changing cumulative arousal in a person that initiates, directs, coordinates, amplifies, terminates, and evaluates the cognitive and motor processes whereby initial wishes and desires are selected, prioritized, operationalized, and (successfully or unsuccessfully) acted out." (Italics is original). This definition acknowledges that L2 motivation is a process, and it is not static rather it is dynamic that fluctuates overtime. This definition also indicates the importance of helping students to sustain or persist in their effort and desire in the process of language learning. In general, it can be concluded that L2 motivation refers the individual's attitude towards learning the target language, the extent to which the individual strives because of the desire to achieve the goal of language learning, and it is a dynamic process. 


\subsection{Motivational Strategies in L2 Teaching Context}

Motivational strategies are techniques and consciously exerted influences that can bring about goal-related behavior and other systematic, long-term positive changes in L2 learning ( Dornyei, 2001). Within the scope of what teachers can do with classes, L2 motivational strategies become teachers' instructional interventions to raise and maintain certain aspects of students' L2 motivation (Guilloteaux \& Dornyei, 2008). These explanations presume that teachers can apply some motivational strategies deliberately in order to enhance students' motivation. Motivational strategies first gained popularity in the 1990s, when the importance of the learning environment in shaping the situated aspects of learners' motivation was highlighted (Dornyei, 2005). Eventually, a number of different scholars proposed various lists of motivational techniques (such as Dörnyei, 1994; Oxford \& Shearin, 1994; Williams \& Burden, 1997; Dornyei \& Csizér, 1998; Dörnyei, 2001) that language teachers could use to improve their teaching by creating a more motivating environment in the classrooms. However, among the proposed list of motivational strategies frameworks, Dornyei's (2001) system of motivational strategies framework is comprehensive and suitable for language teachers to apply them in their classroom.

Dornyei's (2001) framework comprises more than 102 specific motivational strategies which are grouped into four phases. The first phase is creating the basic motivational conditions, namely, laying the foundations of motivation through establishing a good teacher-student rapport, a pleasant and supportive classroom atmosphere, and a cohesive learner group with appropriate group norms. The second phase is generating initial motivation, i.e., by using strategies designed to develop positive attitudes toward the language course and language learning in general, and to increase the learners' expectancy of success. The third phase is maintaining and protecting motivation. This could be achieved by providing learners with experiences of success, by allowing them to maintain a positive social image, and by promoting learner autonomy. The last phase is encouraging positive retrospective self-evaluation. This could be achieved through the promotion of adaptive attributions and the provision of effective and encouraging feedback, as well as by increasing learner satisfaction and by offering grades in a motivational manner. According to Dornyei (2001), the four phases in this framework are built on each other so that students' motivation is created, generated, maintained and encouraged.

In this study, therefore, Dornyei's (2001) system of motivational strategies framework was utilized to investigate teachers and students' perceived importance of motivational strategies in Ethiopian foreign language context.

\subsection{Motivational Strategies Studies in L2 Learning}

In the past, L2 motivation researches were focusing on what motivation is as an abstract concept, rather than focusing on how to enhance student's motivation (Dornyei \& Otto, 1998; Cheng \& Dornyei, 2007). However, following Dornyei's (2001) system of motivational strategies framework, a number of motivational strategies studies have been conducted worldwide. For instance, Dornyei and Csizér (1998) conducted the most influential study on motivational strategies in which they analyzed Hungarian English teachers' rating of the perceived importance and perceived frequency of using 51 motivational strategies. After Dornyei and Csizér's study, numerous replica studies were conducted in different countries such as Cheng and Dornyei (2007) in Taiwan; Alrabai (2011) in Saudi Arabia; Ruesch et al. (2012) in the United States of America, Astuti (2013) in Indonesia, and Fatuma (2014) in Ethiopia etc. All the studies generally followed the same methodological framework and relied on self-reports to explore the perceived importance and perceived frequency of using motivational strategies in the classrooms. These studies contributed a lot in moving the motivational strategies research agenda forward. The contributions include:

p providing empirical evidence supporting the importance and use of motivational strategies,

$>$ demonstrating that some strategies are perceived differently across different cultural contexts,

$>\quad$ And indicating that many motivational strategies are underutilized compared to their perceived 
importance.

\section{Methods and Materials}

\subsection{Research Design}

The main purpose of this study was to empirically identify most important motivational strategies as perceived by teacher and student participants in the research setting. To achieve this purpose, the researcher employed a quantitative methodology. Quantitative methodology is best when researchers need to investigate opinions or perceptions (Cresswell, 2009). Among the different quantitative designs, a survey design was employed. Survey research is used to determine individual beliefs, opinions and attitudes about different issues (Cohen, Manson, \& Morrison, 2007; Creswell, 2012). As the researcher collects data at one point in time, among the different types of survey designs, a cross-sectional survey design was employed. Cross-sectional design is the most popular form of survey design used in educational research (Cohen et al., 2007), and it is handy to examine current attitudes, beliefs, opinions, or practices (Cresswell, 2012).

\subsection{Setting and Participants}

This study was conducted at Nekemte town, in East Wollega, Ethiopia. To investigate teachers' perceived importance of motivational strategies, 65 English language teachers from eight secondary schools in East Wollega, Ethiopia (i.e., Biftu Nakemte, Darge, Dalo, Keso, Kiba Wacha, Gute, Diga and Sasiga), were selected by using convenience sampling. In this context, convenience sampling means the persons participating in the study were chosen because they were readily available for the study (Mertens, 2010; Cresswell, 2012). In addition, to investigate students' perceived importance of motivational strategies, 177 student participants were selected using stratified purposeful sampling. Stratified purposeful sampling is a combination of sampling strategies such that sub-groups are chosen based on specified criteria, and a sample of cases is then selected within those strata (Mertens, 2010). Accordingly, the aforementioned secondary schools were treated like a population on their own, and 25 students from each secondary school (stratum) were selected.

\subsection{Research Instruments}

To collect data, two sets of motivational strategy questionnaires one of which for teachers and the other for students were used. Each questionnaire consists of 55 motivational strategies. The students' motivational strategy questionnaire is similar with that of the teachers' except the minor modification made to suit with the students' perspective. The current researcher adapted the questionnaire from Cheng and Dornyei's (2007) study. Hence, a modification was made on the design of the questionnaire to suit for the context of this study and some items were removed and some other items were added. Accordingly, an attempt was made to consult different motivation theories and L2 motivation studies to incorporate new motivational strategies that were tested and evaluated in different EFL learning contexts.

Cheng and Dornyei's motivational strategy questionnaire has 48 micro motivational strategies which are grouped under 10 macro motivational strategies (See the definition of macro and micro in section-1. Each macro motivational strategy is made up of a set of interrelated micro motivational strategies. For example, 'proper teacher behavior' is a macro motivational strategy and under this strategy, there are a number of micro motivational strategies such as 'show students you care about them' and 'establish good rapport with students'. The participants were asked to rate each motivational strategy on a six-point Likert-Scale ranging from Strongly Disagree to Strongly Agree in terms of how important they consider the use of each strategy for the purpose of enhancing students' English language learning motivation. Furthermore, to eliminate even the slightest risk that English language competence would be a barrier for student participants, the English language version of the questionnaire was translated into Afan Oromo the students' mother tongue. The reliability of the teachers and students' questionnaire was tested by means of Cronbach's Alpha coefficient, and it was found .98 and .94, 
Mekuria, Z. B.

respectively.

\section{Results and discussions}

In this study, an attempt was made to identify most important macro and micro motivational strategies which promote students' motivation. To this effect, two sets of questionnaire containing an exhaustive list of motivational strategies were administered for teacher and student participants. The first two research questions concerned with identifying the rank order of motivational strategies depending on their importance as perceived by the participants both at macro and micro levels. The third research question, however, sought to identify 15 most important micro motivational strategies as perceived by teacher and student participants. To analyze and interpret the collected data, a descriptive statistics, i.e., 'mean' and 'standard deviation' were computed.

\subsection{Teachers' Perceived Importance of Motivational Strategies}

The first research question of this study mainly inquired macro and micro motivational strategies which English language teacher participants perceived as most important in facilitating students' English language learning motivation. Accordingly, in the next sub-sections, the analyses and discussions of macro and micro motivational strategies are presented, respectively.

Teachers' Perceived Importance of Macro Motivational Strategies - One of the aims of administering teachers' questionnaire was to assess the perceived importance of macro motivational strategies. The questionnaire has 10 macro motivational strategies, and each macro motivational strategy was made up of a set of interrelated micro motivational strategies. Accordingly, the mean value of all these related micro motivational strategies in each macro motivational strategy was taken to determine the importance attached to a particular macro motivational strategy. Hence, the mean score of each macro motivational strategy was calculated by summing up the scores of the micro motivational strategies and then dividing the summed score by the number of the micro motivational strategies. Furthermore, a comparison between the findings of the current study and the findings obtained from Cheng and Dornyei's (2007) study on Taiwanese teachers of English was also made. Cheng and Dornyei's (2007) study was selected for the comparison because the questionnaire of the current study was mainly adapted from their study. Table 1 below presents the current study's rank order together with Cheng and Dornyei's (2007) study rank order of macro motivational strategies.

\section{Table 1}

Comparison of rank order and descriptive statistics of the macro motivational strategies

\begin{tabular}{|c|c|c|c|c|c|}
\hline Macro Motivational Strategies rank order & $\begin{array}{c}\text { No of } \\
\text { strategies }\end{array}$ & $n$ & Mean & $S D$ & $\begin{array}{c}\text { Cheng \& } \\
\text { Dornyie' } \\
\text { (2007) rank }\end{array}$ \\
\hline 1. Increase learners' goal-orientedness $(\alpha=0.90)$ & 4 & 65 & 4.83 & 1.36 & 6 \\
\hline 2. Promote learners' self-confidence $(\alpha=0.93)$ & 8 & 65 & 4.70 & 1.34 & 3 \\
\hline 3. Recognize students' effort $(\alpha=0.89)$ & 5 & 65 & 4.68 & 1.35 & 2 \\
\hline 4. Present tasks properly $(\alpha=0.76)$ & 3 & 65 & 4.65 & 1.36 & 5 \\
\hline 5. Familiarize learners with L2-related values $(\alpha=0.91)$ & 6 & 65 & 4.63 & 1.33 & 8 \\
\hline 6. Proper teacher behavior $(\alpha=0.83)$ & 5 & 65 & 4.57 & 1.31 & 1 \\
\hline 7. Promote group cohesiveness and group norms $(\alpha=0.89)$ & 5 & 65 & 4.56 & 1.30 & 9 \\
\hline 8. Promote learner autonomy $(\alpha=0.88)$ & 6 & 65 & 4.55 & 1.33 & 10 \\
\hline 9. Creating a pleasant classroom climate $(\alpha=0.75)$ & 6 & 65 & 4.29 & 1.44 & 4 \\
\hline 10. Make the learning tasks stimulating $(\alpha=0.79)$ & 7 & 65 & 4.29 & 1.46 & 7 \\
\hline
\end{tabular}

As shown in Table 1, the result obtained from the teachers' motivational strategy questionnaire data indicates that from six point Likert-Scale, the mean values of the macro motivational strategies range from 4.83 to 4.29 ( i.e., the maximum is 4.83 and the minimum is 4.29). These values suggest that there is a subtle difference among the ten motivational clusters in terms of their importance to promote students' motivation as perceived by teacher participants in the research setting. Despite the subtle mean value differences, Table 1 shows that the participants perceived 'increase learners' goal-orientedness', 'promote learners' self-confidence', and 'recognize 
students' effort' as the $1^{\text {st }}, 2^{\text {nd }}$ and $3^{\text {rd }}$ important macro motivational strategies, respectively. On the other hand, Table 1 demonstrates that there is a shared as well as a mismatch of perception on the importance of the ten macro motivational strategies between the findings in the current study and Cheng \& Dornyei's (2007) study. The detail description, analysis and discussion of each macro motivational strategy are presented below based on their rank order.

As illustrated in Table 1, the first ranked macro motivational strategy was 'Increase learners' goal-orientedness' $(\mathrm{M}=4.83 ; \mathrm{SD}=1.36)$. From this finding, it can be discerned that increasing learners' goal-orientedness is recognized as most important macro motivational strategy to enhance students' motivation by teacher participants in the research setting. This macro motivational strategy is one of the strategies used for generating learners' initial motivation in Dornyei's (2001) system of motivational strategies framework (See Section 2.2). According to Dornyei, the most powerful way to increase the learners' goal-orientedness is goal setting. Pertaining to goal setting, Oxford and Sherian (1994) highlighted that goal setting can have exceptional importance in stimulating L2 learning motivation. Similarly, Alderman (2004) asserted that goal setting influences learning and motivation by providing a target and information about how well one is doing to achieve the goal. On the other hand, while this macro motivational strategy received the $1^{\text {st }}$ rank order in the current study, it received $6^{\text {th }}$ rank order in Cheng and Dornyei's (2007) study. The finding, therefore, reflects a lack of conformity on this macro motivational strategy between the two studies in terms of promoting students' motivation.

The second ranked macro motivational strategy was 'Promote learners' self-confidence' ( $\mathrm{M}=4.70 ; \mathrm{SD}=1.34)$. This finding, therefore, reflects that teacher participants recognized the importance of promoting learners' self-confidence as most important strategy to promote students' motivation. Increasing learners' self-confidence is one of the important macro motivational strategies for maintaining and protecting students' motivation in Dornyei's (2001) system of motivational strategies framework. In this regard, Williams and Burden (1997) and Dornyei and Ushioda (2011) explicate that students' confidence play key roles in maintaining motivation, however, students will not be able to progress if they have any doubts about their abilities. The teacher participants' recognition is, therefore, in line with what is established in literature that encouraging the learner in a way which can explicitly make the learner aware of personal strength and abilities has a fundamental effect on the amount of effort they exert on learning (Dornyei, 1994; Good \& Brophy, 2003). Furthermore, this macro motivational strategy received the $3^{\text {rd }}$ rank order in Cheng and Dornyei's (2007) study. This finding, therefore, suggests that there is a shared perception between the two studies participants on the importance of promoting learners' self-confidence to enhance students' motivation.

As Table 1 indicates, the macro motivational strategy 'Recognize students' effort' ( $M=4.68 ; \mathrm{SD}=1.35$ ) received the third rank order. This finding is in line with the idea that receiving recognition and evidence of success will support learners' intrinsic feelings of satisfaction (Cheng \& Yeh, 2009). In addition, Oxford and Sherian (1994) proposed that language learners will feel continuously motivated if the effort they are exerting on tasks is viewed as leading to significant outcomes. They also added that if language learners do not believe that their performance leads somewhere that is ultimately valuable, their motivation will be lowered. This finding, thus, demonstrates that teacher participants in the research setting perceived the importance of recognizing students' effort to enhance students' motivation. On the other hand, a consistent rank order was obtained between the two studies on this macro motivational strategy. It received the $3^{\text {rd }}$ and $2^{\text {nd }}$ rank order in the current study and in Cheng and Dornyei's (2007) study, respectively. This finding reflects that there is a shared perception between the two studies participants on the importance of recognizing students' effort to promote students' motivation.

The fourth ranked macro motivational strategy in promoting students' motivation was 'Present tasks properly' $(\mathrm{M}=4.65 ; \mathrm{SD}=1.36)$. In connection with this cluster, Anderman and Anderman (2010) explain that interesting tasks have been viewed as one of the greatest components of motivation. More specifically, they explain that the way teachers present tasks can be either motivating or demotivating depending on teachers' administration of the tasks. This finding, therefore, reflects that teacher participants in the research setting are 
aware of the reality that presenting tasks properly promotes students' motivation. Furthermore, Table 1 demonstrates that this macro strategy received the $4^{\text {th }}$ and $5^{\text {th }}$ rank order in the current study and in Cheng and Dornyei's (2007) study, respectively. This finding, therefore, reflects that there is a shared perception between the two studies participants on the importance of presenting tasks properly to facilitate students' motivation.

The fifth rank ordered macro motivational strategy was 'Familiarize learners with L2-related values' $(\mathrm{M}=$ 4.63; $\mathrm{SD}=1.33$ ). This cluster is in line with the social psychological view of L2 motivation which proposed that language learners' dispositions towards the target culture and its people have a considerable influence on their learning achievement (Dornyei, 2005). Pertaining to this idea, Brown (1989) highlights that learning a foreign language also involves learning the culture of the target language communities to some degree, regardless of the fact that the learner might not have or will not set foot in the native language country because language and culture are bound up with each other and interrelated. Accordingly, Dornyei (2001) specifically explained that the most far-reaching consequences in motivating L2 learners can be achieved by promoting positive language-related values and attitudes. On the other hand, 'Familiarize learners with L2-related values' received $5^{\text {th }}$ and $8^{\text {th }}$ rank order in the current study and in Cheng and Dornyei's (2007) study, respectively. From this finding, it can be discerned that there is a mismatch of perception between the two studies participants on the importance of familiarizing learners with L2-related values to promote students' motivation.

The macro motivational strategy which appeared at the sixth rank order was 'Proper teacher behavior' ( $\mathrm{M}=$ 4.57; $\mathrm{SD}=1.31$ ). In Dornyei's (2001) system of motivational strategies framework, proper teacher behavior is one of the pre-conditions that must be in place before employing motivational strategies to generate student motivation. In the framework, proper teacher behavior is represented by many aspects of the language teacher's behavior, like enthusiasm towards teaching, commitment to students' learning and development of a positive relationship with learners, etc. From the current study participants' perspective, 'proper teacher behavior', received the $6^{\text {th }}$ rank order which is not in a good agreement with that of Cheng and Dornyei's (2007) study, which is $1^{\text {st }}$ rank order. This finding, therefore, reflects that there is a mismatch of perception between the two studies participants on the importance of proper teacher behavior to promote students' motivation.

The macro motivational strategy which received the seventh rank order was 'Promote group cohesiveness and group norms' (M=4.56; $\mathrm{SD}=1.3)$. According to Dornyei (2001), creating a cohesive learner group with appropriate group norms has a direct motivational influence on students learning, thus, establishing constructive group norms in language classroom is important. However, Dornyei reminds that norms need to be explicitly discussed and willingly adopted by members. On the other hand, 'Promote group cohesiveness and group norms' received $9^{\text {th }}$ rank order in Cheng and Dornyei's (2007) study. Therefore, it may be inferred that there is a shared perception between the two studies participants on the importance of promoting group cohesiveness and group norms to enhance students' motivation.

The other motivational cluster that appeared at the eighth rank order was 'Promote learner autonomy' $(\mathrm{M}=$ 4.55; $\mathrm{SD}=1.33$ ). Pertaining to this cluster, Deci and Ryan's (1985) work on self-determination theory has highlighted the fact that an autonomy-supporting environment leads to increased intrinsic motivation. The link between autonomy and motivation has also been recognized in the L2 field, for example Ushioda (1996) explicitly states that autonomous language learners are by definition motivated learners. Accordingly, Dornyei and Ushioda (2011) suggest that language teachers can foster learning autonomy in different ways, including sharing learning responsibilities, involving them in making decisions regarding classroom materials, and giving them positions of authority through peer teaching and project work. On the other hand, 'promote learner autonomy' received $10^{\text {th }}$ rank order in Cheng and Dornyei's (2007) study. This finding, therefore, may reflect that there is a shared perception between the two studies participants on the importance of promoting learner autonomy to enhance students' motivation.

The ninth rank ordered macro motivational strategy was 'Creating a pleasant classroom climate' (M=4.29; $\mathrm{SD}=1.44)$. Although it received the ninth rank order in current study, in Dornyei's (2001) system of motivational 
strategies framework, creating a pleasant and supportive classroom atmosphere is one of the pre-conditions that must be in place before employing motivational strategies to generate student motivation. Moreover, Alderman (2004) asserts that if optimum motivation is to happen, a major priority is to build a pleasant classroom climate in which students support each other for learning and not only want to achieve, but also care about their classmates' achievement. On the other hand, Table 1 indicates that there is also lack of conformity on this macro motivational strategy between the two studies. It received $4^{\text {th }}$ rank order in Cheng and Dornyei's (2007) study. This finding, therefore, reflects that there is a mismatch of perception between the two studies participants on the importance of creating a pleasant classroom climate to promote students' language learning motivation.

The tenth and the least ranked macro motivational strategy was 'Make the learning tasks stimulating' $(\mathrm{M}=4.29 ; \mathrm{SD}=1.46)$. Most motivational psychologists broadly believe that making the learning process more stimulating and enjoyable would greatly contribute to sustained learner involvement, and this assumption makes a lot of sense to classroom teachers (Dornyei, 2001). Dornyei further explained that students will not be motivated to learn unless they regard the material they are taught as worth learning. Furthermore, he added that despite the fact that textbooks do not entirely address the students' needs, for various reasons teachers are pretty much stuck with the ready-made text books. However, to make textbooks motivating, it is expected of teachers to relate the subjects to the everyday experiences and backgrounds of the students (Dornyei, 2001). On the other hand, 'make the learning tasks stimulating' received $10^{\text {th }}$ and $7^{\text {th }}$ rank order in the current study and in Cheng and Dornyei's (2007) study, respectively. This finding, therefore, reflects that there is lack of conformity on this motivational cluster in terms of enhancing students' language learning motivation.

Teachers' Perceived Importance of Micro Motivational Strategies - In addition to ranking macro motivational strategies, the first research question also sought to identify the rank order of micro motivational strategies. Accordingly, teacher participants were provided a menu of 55 micro motivational strategies, and they were asked to rate the strategies in terms of their importance in promoting students' English language learning motivation. Table 2 below, thus, illustrates the rank order of the top selected ten micro motivational strategies with their mean and standard deviation values.

\section{Table 2}

Rank order and descriptive statistics of the top ten strategies as perceived by teachers

\begin{tabular}{clccc}
\hline No. & \multicolumn{1}{c}{ Micro Motivational strategies } & $n$ & Mean & $S D$ \\
\hline 1 & establish good rapport (relationship) with students & 65 & 5.21 & 1.11 \\
2 & encourage students to set learning goals & 65 & 5.11 & 1.34 \\
3 & recognize students' effort and achievement & 65 & 5.08 & 1.20 \\
4 & encourage students to ask and answer questions. & 65 & 5.06 & 1.30 \\
5 & reduce students' language anxiety when they are speaking in English & 65 & 5.05 & 1.35 \\
6 & use a short and interesting opening activity to start each class & 65 & 5.03 & 1.24 \\
7 & encourage students to use English outside the classroom & 65 & 5.03 & 1.34 \\
8 & provide students with positive feedback & 65 & 4.98 & 1.35 \\
9 & give good reasons to students as to why a particular task is meaningful & 65 & 4.97 & 1.27 \\
10 & give students choices in deciding how and when they will be assessed & 65 & 4.88 & 1.23 \\
\hline
\end{tabular}

As Table 2 above illustrates, there is only a slight difference in terms of mean value among the ten top identified individual strategies i.e., their mean value ranges from 5.21 to 4.88. This subtle mean difference implies that the teacher participants placed importance on these individual strategies nearly equally in terms of promoting students' English language learning motivation in the research setting. The detail analysis and discussion of the selected micro strategies are given in the next section.

\subsection{Students' Perceived Importance of Motivational Strategies}

Similar to the first research question, the second research question also sought to identify the rank order of macro and micro motivational strategies in terms of their importance for enhancing students' motivation as perceived by student participants. The students' questionnaire data analysis followed the same procedure 
Mekuria, Z. B.

involved with that of the teachers' questionnaire data analysis.

Students' Perceived Importance of Macro Motivational Strategies - The rank order and descriptive statistics of the ten macro motivational strategies are described in the Table 3 below. Here, it should be noted that the rank order of the macro motivational strategies, in similar manner with teachers' data, is based on the importance attached by student respondents to the micro motivational strategies found under each macro motivational strategy.

\section{Table 3}

Rank order and descriptive statistics of macro motivational strategies as perceived by student participants

\begin{tabular}{|c|c|c|c|c|}
\hline Macro Motivational Strategies rank order & $\begin{array}{c}\text { No of } \\
\text { strategies }\end{array}$ & $n$ & Mean & $S D$ \\
\hline 1. Increase learners' goal-orientedness $(\alpha=0.66)$ & 4 & 177 & 4.30 & 1.51 \\
\hline 2. Recognize students' effort $(\alpha=0.54)$ & 8 & 177 & 4.294 & 1.54 \\
\hline 3. Present tasks properly $(\alpha=0.46)$ & 5 & 177 & 4.28 & 1.42 \\
\hline 4. Proper teacher behavior $(\alpha=0.57)$ & 3 & 177 & 4.22 & 1.48 \\
\hline 5. Promote learners' self-confidence $(\alpha=0.70)$ & 6 & 177 & 4.18 & 1.50 \\
\hline 6. Creating a pleasant classroom climate $(\alpha=0.61)$ & 5 & 177 & 4.09 & 1.48 \\
\hline 7. Promote group cohesiveness and group norms $(\alpha=0.57)$ & 5 & 177 & 4.09 & 1.53 \\
\hline 8. Promote learner autonomy $(\alpha=0.67)$ & 6 & 177 & 4.05 & 1.48 \\
\hline 9. Familiarize learners with L2-related values $(\alpha=0.74)$ & 6 & 177 & 3.95 & 1.63 \\
\hline 10. Make the learning tasks stimulating $(\alpha=0.64)$ & 7 & 177 & 3.89 & 1.59 \\
\hline
\end{tabular}

As it has been presented in Table 3 above, the mean value of the ten macro motivational strategies ranges from 3.89 to 4.30 (i.e., minimum 3.89 and maximum 4.30). The result, analysis and discussion of the ten macro motivational strategies are presented below based on their rank order.

The macro strategy 'Increase learners' goal-orientedness' ( $\mathrm{M}=4.30 ; \mathrm{SD}=1.51)$ took the first rank order. The most striking result regarding this macro strategy is that teachers also perceived it as the first rank order (See Table 1). The evidence from this study, therefore, suggests that there is a shared perception between the teacher and student participants on the importance of this macro strategy in promoting students' motivation. The second ranked macro strategy was 'Recognize students' effort' $(\mathrm{M}=4.294 ; \mathrm{SD}=1.54)$. This strategy received the third rank order in the finding of the teachers (See Table 1) which is in a good agreement with the student participants. This finding, therefore, imply that there is a shared perception between teacher and student participants on the importance of recognizing students' effort for enhancing students' motivation. The macro strategy, 'Present tasks properly' $(\mathrm{M}=4.28 ; \mathrm{SD}=1.42)$ received the third rank order. A consistent rank order was obtained on this macro strategy between teacher and student participants, i.e., $4^{\text {th }}$ and $3^{\text {rd }}$ rank order, respectively (See Table 1). This finding, therefore, reflects that there is a shared perception between teacher and student participants on the importance of presenting tasks properly to facilitate students' motivation.

The fourth ranked macro strategy was 'Proper teacher behavior' $(\mathrm{M}=4.22 ; \mathrm{SD}=1.48)$. The students' rank order of this macro strategy is not in a good agreement with that of the teachers, which is the $6^{\text {th }}$ rank order (See Table 1). This finding, therefore, may imply that there is a mismatch of perception between teacher and student participants on the importance of proper teacher behavior for enhancing students' motivation. On the other hand, the macro strategy, 'Promote learners' self-confidence' $(\mathrm{M}=4.18 ; \mathrm{SD}=1.50)$, received the $5^{\text {th }}$ rank order. There is lack of conformity between student and teacher participants on the rank order of this macro strategy because it received the $2^{\text {nd }}$ rank order by the teacher participants (See Table 1). This finding, therefore, reflects that there is a mismatch of perception between student and teacher participants on the importance promoting learners' self-confidence to promote students' motivation.

The sixth ranked macro strategy was 'creating a pleasant classroom climate' $(\mathrm{M}=4.09 ; \mathrm{SD}=1.48)$. From the teacher participants' perspective, this strategy received the $9^{\text {th }}$ rank order (See Table 1) which is not in a good agreement with that of student participants' perspective. This finding, therefore, reflects that there is a mismatch of perception between teacher and student participants on the importance of creating a pleasant classroom 
climate to promote students' motivation. The seventh ranked macro strategy was 'promote group cohesiveness and group norms' $(\mathrm{M}=4.09 ; \mathrm{SD}=1.53)$. Pertaining to this strategy, a consistent rank order was obtained between teacher and student participants in which in both cases the cluster received the $7^{\text {th }}$ rank order (See Table $1 \& 3$ ). This finding, therefore, reflects that there is a shared perception between teacher and student participants on the importance of promoting group cohesiveness and group norms to facilitate students' motivation. On the other hand, the eighth ranked macro motivational strategy was 'Promote learner autonomy' $(\mathrm{M}=4.05 ; \mathrm{SD}=1.48)$. In similar manner with the student participants, this macro strategy received the $8^{\text {th }}$ rank order by the teacher participants (See Tables $1 \& 3$ ). This finding, therefore, demonstrates that there is a shared perception between teacher and student participants on the importance of promoting learner autonomy to enhance students' English language motivation.

The ninth rank ordered macro strategy was 'familiarize learners with L2-related values' (M=3.95; $\mathrm{SD}=1.63)$. This strategy received $9^{\text {th }}$ and $5^{\text {th }}$ rank order in the student and teacher participants, respectively (See Table $1 \&$ 3). This finding, therefore, implies that there is a mismatch of perception between student and teacher participants on the importance of familiarizing learners with L2-related values to promote students' motivation. Finally, the tenth rank ordered macro strategy was 'make the learning tasks stimulating' $(\mathrm{M}=3.89 ; \mathrm{SD}=1.59)$. The student participants rank order of this macro strategy is consistent with the teacher participants, which is the $10^{\text {th }}$ rank order (See Table 1). From this finding, therefore, it can be discerned that there is a shared perception between teacher and student participants on the importance of making the learning tasks stimulating to facilitate students' motivation.

Students' Perceived Importance of Micro Motivational Strategies - On top of identifying the rank order of macro motivational strategies, the second research question also sought to identify the rank order of micro motivational strategies as perceived by student respondents. To this effect, student participants were provided a menu of 55 micro motivational strategies and asked to rate the strategies based on their importance in enhancing students' motivation. Accordingly, based on the perceived importance placed by the student respondents on the 55 micro motivational strategies, the rank order of the ten most important micro motivational strategies were identified. The rank order of the top ten micro motivational strategies with their mean and standard deviation values are presented in Table 4 below.

\section{Table 4}

Rank order and descriptive statistics of the top selected micro motivational strategies as perceived by students

\begin{tabular}{clccc}
\hline No. & \multicolumn{1}{c}{ Micro Motivational Strategies } & $n$ & Mean & SD \\
\hline 1 & provide face to face feedback to students about their progress & 177 & 4.60 & 1.50 \\
2 & encourage students to set learning goals & 177 & 4.56 & 1.52 \\
3 & give clear instructions by modelling & 177 & 4.56 & 1.37 \\
4 & bring in and encourage humor & 177 & 4.54 & 1.46 \\
5 & encourage students to ask and answer questions. & 177 & 4.53 & 1.35 \\
6 & make sure grades (marks) reflect students' effort and hard work & 177 & 4.51 & 1.41 \\
7 & reduce SS' language anxiety when they are speaking in English & 177 & 4.47 & 1.41 \\
8 & give good reasons to students as to why a particular task is meaningful & 177 & 4.47 & 1.45 \\
9 & remind students of the benefits of mastering English & 177 & 4.41 & 1.61 \\
10 & show students how individual activity help them to attain their goal & 177 & 4.37 & 1.39 \\
\hline
\end{tabular}

As it can be seen from Table 4, the mean values of the top ten identified micro motivational strategies by the student participants ranges from 4.37 to 4.60 . These mean values suggest that the student participants placed almost equal importance for the top ten identified micro motivational strategies in terms of enhancing students' English language learning motivation. The detail analysis and discussions of the selected micro motivational strategies are given in the next section.

\subsection{Important micro motivational strategies as perceived by teachers and students}

The third research question of this study wanted to identify the top 15 micro motivational strategies which 
are perceived most important in facilitating students' English language learning motivation as perceived by teacher and student participants. Only 15 motivational strategies were selected because a few well-chosen motivational strategies that suit both teachers and their students might create an overall positive motivational climate in the classroom (Dornyei, 2001). Accordingly, the top 10 identified strategies by teachers and students were brought together, and they were compared and contrasted and finally 15 most important motivational strategies were identified. To identify the rank order of motivational strategies, a descriptive statistics i.e., 'mean' and 'standard deviation' were computed.

Table 5 below, therefore, revealed that the comparison and contrast between teachers and students' findings demonstrated that there is a shared as well as a mismatch of perception on the importance of the 15 motivational strategies. Pertaining to the shared perception which is an encouraging finding, Table 5 indicates that four micro motivational strategies were commonly selected by teacher and student participants. On the other hand, the findings indicated that there was a mismatch of perception between teacher and student participants on eleven micro motivational strategies. The finding, therefore, reflects that motivational strategies that are perceived most important for teachers may not conform for students vice versa.

\section{Table 5}

Most important motivational strategies as perceived by teacher and student participants

\begin{tabular}{llc}
\hline No. & \multicolumn{1}{c}{ Top 15 Most Important Motivational strategies } & Selected by \\
\hline 1 & establish good rapport (relationship) with students & Teacher \\
2 & encourage students to set learning goals & Both \\
3 & recognize students' effort and achievement & Teacher \\
4 & encourage students to ask and answer questions. & Both \\
5 & reduce students' language anxiety when they are speaking in English & Both \\
6 & use a short and interesting opening activity to start each class & Teacher \\
7 & encourage students to use English outside the classroom & Teacher \\
8 & provide students with positive feedback & Teacher \\
9 & give good reasons to students as to why a particular task is meaningful & Both \\
10 & give students choices in deciding how and when they will be assessed & Teacher \\
11 & give clear instructions by modelling & Students \\
12 & bring in and encourage humor & Students \\
13 & make sure grades (marks) reflect students' effort and hard work & Students \\
14 & remind students of the benefits of mastering English & Students \\
15 & show students how individual activity help them to attain their goal & Students \\
\hline
\end{tabular}

As Table 5 above shows the strategy, 'Establish good rapport (relationship) with students' was selected by only teacher participants. Regarding this strategy, Dornyei (2001) explicated that language teachers who share warm personal interactions with their students, who respond to students concerns in an empathic manner and who succeed in establishing relationships of mutual trust and respect with the learners are more likely to inspire them in academic matters than those who have no personal ties with the learners. Nevertheless, Dornyei reminds that teacher relationship with students depends on the cultural context of the country, in general, and the specific area, in particular. The other strategy, 'Encourage students to set learning goals' was selected by both teacher and student participants. In connection with this strategy, Alderman (2004) explains that goal setting influences learning and motivation by providing a target and information about how well one is doing. Similarly, Oxford and Sherian (1994) emphasized the importance of goal-setting in learning L2 by explaining that goal setting can have exceptional importance in stimulating a foreign language learning motivation. Furthermore, goal setting can be used in the educational setting as a powerful motivational strategy (Brophy, 2004 as cited in Alshehri, 2013).

In addition, the strategy 'recognize students' effort and achievement' was identified by only teacher participants. In connection with this strategy, Oxford and Sherian (1994) indicated that if language learners do not believe that their performance leads somewhere that is ultimately valuable, their motivation will be lowered. The other identified strategy by teacher and student participants was 'Encourage students to ask and answer questions'. Pertaining to this strategy, Alderman (2004) explains that establishing a classroom climate where 
students are encouraged to ask and answer questions is a crucial strategy to promote students' motivation. Similarly, the other strategy selected by both teacher and student participants was 'reduce students' language anxiety when they are speaking in English'. Pertaining to this strategy, Dornyei (1996) argues that learners who are less anxious, have better previous experiences with using the second language, evaluate their own proficiency more highly, and consider the learning tasks less difficult. This implies that reducing students' language anxiety when they are speaking in English is a crucial strategy to promote students' motivation. In addition, the strategies, 'use a short opening activity to start each class', and 'encourage students to use English outside the classroom' were selected by only teacher participants. According to Dornyei's (2001) system of motivational strategies framework, these strategies are helpful in creating a pleasant classroom climate in language learning.

Furthermore, the strategies 'Provide students with positive feedback' and 'provide face to face feedback to students about their progress', were identified by teacher and student participants, respectively. According to Ur (1996) and Harmer (2001), to have a motivational impact the feedback provided by teachers should indicate the particular area of strength, or achievement, or progress of the learner and be given promptly. Similarly, the strategy 'Give good reasons to students as to why a particular task is meaningful' was also identified by teacher and student participants. With regard to this strategy, Anderman and Anderman (2010) explain that the way teachers present tasks can be either motivating or demotivating depending on teachers' administration of the tasks. This includes clarifying the aim of the task, arousing learners' anticipation toward the task, and offering suitable strategies for doing the task. In addition, Alderman (2004) indicates that motivation for instruction demands teachers not only to bring the task to the students, but also to bring students to the task. This means, specific task characteristics will attract student attention and interest. Therefore, providing good reasons to students as to why a particular task is meaningful is one of the pertinent motivational strategies that make language learning stimulating and enjoyable.

The other identified strategy by only teacher participants was 'give students choices in deciding how and when they will be assessed'. Giving students choices in deciding how and when they will be assessed is one of the strategies to promote learner autonomy (Dornyei, 2001). Regarding autonomy, Deci and Ryan (1985) highlighted the fact that an autonomy-supporting environment leads to increased intrinsic motivation. On the other hand, the strategy 'Give clear instructions by modeling' was identified by only student participants. When giving task instructions, Dornyei (2001) explains that demonstrating the task and illustrating some of the strategies that might be particularly effective during task completion is important as it can effectively sort out any confusion or lingering doubts. He added that the best way to demonstrate the necessary strategies and skills is to model them.

Another top selected strategy by student respondents was 'Bring in and encourage humor'. According to Dornyei (2001), a further tool to improve the classroom atmosphere is the use of humor. Accordingly, Dornyei and Csizér (1998) wrote that foreign language teachers should bring in humor, laughter and smiles, do fun things in class, and have game-like competitions. Furthermore, Alrabai (2010) reported that making learning tasks more attractive by adding new and humorous elements have been found to be important strategies for making learning stimulating and enjoyable. However, Dornyei (2001) explained that the main point about having humor in the classroom is not so much about continuously cracking jokes but rather having a relaxed attitude about how seriously we take ourselves. Another top identified strategy by student participants was 'Make sure grades (marks) reflect students' effort and hard work'. In connection with this strategy, Dornyei (2001) reminds that offering marks or grades in a motivating manner can help students' positive self-evaluation of foreign language learning.

A further strategy which was selected by student participants was 'Remind students of the benefits of mastering English'. According to Dornyei (2001), there are three relatively separate value dimensions in learning a foreign language: intrinsic, integrative and instrumental value. This strategy, therefore, relates with the instrumental value which focuses the pragmatic benefits that the mastery of the target language might bring 
about. With regard to this, Ellis (1998) stated that learners with an instrumental reason for learning L2 can be successful. To this effect, discussions about the life application value of knowing the target language is a crucial strategy to create associations between target language proficiency and desirable outcomes (Dornyei, 2001). The other top selected strategy by student respondents was 'Show students how individual activity helps them to attain their goal'. Showing students how individual activity helps them to attain their goal is an important strategy because it directs students' attention and effort towards goal-relevant activities (Dornyei, 2001). Consequently, it affects students' performance of doing activities.

\section{Conclusions and implications}

Based on the findings of the current study, significant conclusions have been drawn. The findings from motivational strategy questionnaires demonstrated that there was a mismatch of perception between teacher and student participants on the importance of motivational strategies. Thus, it can be concluded that there is a gap between teacher and student participants pertaining to what promotes students' motivation to learn English. Hence, to create an overall motivational climate in the classroom, it is expected of teachers to bridge this gap. Motivational strategy is not considered motivating only because a teacher perceived it important and implemented it during a lesson (Smith, 2016). This implies that to motivate students more effectively, considering students' sentiment toward motivational strategies is crucial. This could be achieved by creating an open dialogue between teacher and students and allowing students to express their beliefs towards their own motivation in learning English and what can promote it. In such a way, teachers can select or develop motivational strategies that suit both teacher and students. Moreover, English language teachers have to stay up to date with developments in motivation theories and use of motivational strategies and need to display as much as they can of such developments in their classes.

Based on the conclusions made, it was suggested that it is important to conduct more studies of this kind at various EFL settings to gain a broader perspective on the perceived importance of motivational strategies in different EFL learning contexts. Accordingly, other researchers can replicate this study adapting instruments to their specific EFL context. More importantly, it is also recommended to replicate this study among primary and preparatory schools to further check the perceived importance of motivational strategies at different levels.

\section{References}

Alderman, M. K. (2004). Motivation for achievement: Possibilities for teaching and learning (2 ${ }^{\text {nd }}$ ed.). London: Mahwah, New Jersey.

Alnatheer, A. (2013). The role of motivation and motivational strategies in Saudi students' communicative competence in English (Doctoral dissertation), Queensland University of Technology, Australia.

Alrabai, F. (2010). The use of motivational strategies in the Saudi EFL classroom (Doctoral dissertation), University of Newcastle, Australia.

Alrabai, F. (2011). Motivational instruction in practice: Do EFL instructors at King Khalid University motivate their students to learn English as a foreign language? Arab World English Journal, 2(4), 257-285.

Anderman, E. M., \& Anderman, L. H. (2010). Classroom motivation. Upper Saddle River, NJ: Merrill.

Astuti, S. P. (2013). Teachers' and students' perceptions of motivational teaching strategies in an Indonesian high school context. TEFLIN Journal, 24(1), 1-18.

Cheng, H. F., \& Dornyei, Z. (2007). The use of motivational strategies in language instruction: The case of EFL teaching in Taiwan. International Journal of Innovation in Language Learning and Teaching, 1(1), 153-174. https://doi.org/10.2167/illt048.0

Cheng, Y. C., \& Yeh, H. T. (2009). From concepts of motivation to its application in instructional design: Reconsidering motivation from an instructional design perspective. British Journal of Educational Technology, 40(4), 597-605. https://doi.org/10.1111/j.1467-8535.2008.00857.x

Cohen, L., Manion, L., \& Morrison, K. (2007). Research methods in education (5 ${ }^{\text {th }}$ ed.). London and New York: Routledge. https://doi.org/10.4324/9780203029053 
Investigating teachers and students' perceived importance of motivational strategies: Case of secondary schools

Cresswell, J. W. (2009). Research design qualitative, quantitative, and mixed methods approaches. Los Angeles: SAGE Publications.

Cresswell, J. W. (2012). Educational research: Planning, conducting and evaluating qualitative and quantitative research ( $4^{\text {th }}$ ed.). Boston: Pearson Education .Inc.

Deci, E., \& Ryan, R. (1985). Intrinsic motivation and self-determination in human behaviour. New York: Plenum Press. https://doi.org/10.1007/978-1-4899-2271-7

Dornyei, Z. (1994). Motivation and motivating in the foreign language classroom. Modern Language Journal, 78, 273-284. https://doi.org/10.1111/j.1540-4781.1994.tb02042.x

Dornyei, Z. (2001). Motivational strategies in the language classroom. Cambridge: Cambridge University Press. https://doi.org/10.1017/CBO9780511667343

Dornyei, Z. (2005). The psychology of the language learner: Individual Differences in second language acquisition. Mahwah, NJ: Lawrence Erlbaum.

Dornyei, Z., \& Csizér, K. (1998). Ten commandments for motivating language learners: Results of an empirical study. Language Teaching Research, 2, 203-229. https://doi.org/10.1177/136216889800200303

Dornyei, Z., \& Ottó, I. (1998). Motivation in action: A process model of L2 motivation. Working Papers in Applied Linguistics, 4, 43-69.

Dornyei, Z., \& Ushioda, E. (2011). Teaching and researching motivation. Harlow: Longman.

Ellis, R. (1994). The study of second language acquisition. Oxford: Oxford University Press.

Ellis, R. (2008). The study of second language acquisition ( $2^{\text {nd }}$ ed.). Oxford: Oxford University Press.

Eshetie, A. B. (2010). Language policies and the role of English in Ethiopia. Presented at the 23rd Annual Conference of International Association of Teachers of English as a Foreign Language Business English Special Interest Group (19-21 Nov. 2010), Bielefeld, Germany.

Fatuma, M. (2014). Investigation into the implementation of motivational strategies: The case of Jimma preparatory school (Masteral thesis), Jima University, Ethiopia.

Gardner, R. (1985). Social psychology and second language learning: The role of attitudes and motivation. London: Edward Arnold.

Good, T., \& Brophy, J. (1994). Looking in classrooms (6 ${ }^{\text {th }}$ ed.). New York: Harper Collins.

Harmer, J. (2001). The practice of English language teaching ( $3^{\text {rd }}$ ed.) London: Longman.

Mertens, D. M. (2010). Research and evaluation in education and psychology: Integrating diversity with quantitative, qualitative, and mixed methods ( $3^{\text {rd }}$ ed.). Thousand Oaks: SAGE Publications, Inc.

Negash, T. (2006). Education in Ethiopia: From crisis to the brink of collapse. Uppsala: Nordiska Afrika institute.

Oxford, R., \& Shearin, J. (1994). Language learning motivation: Expanding the theoretical framework. Modern Language Journal, 78, 12-28. https://doi.org/10.1111/j.1540-4781.1994.tb02011.x

Ruesch, A., Bown, J., \& Dewey, D. (2012). Student and teacher perceptions of motivational strategies in the foreign language classroom. Innovation in Language Learning and Teaching, 6, 15-27. https://doi.org/10.1080/17501229.2011.562510

Smith, K. (2016). A Mixed Methods Study of Motivational Teaching Strategies in the ESL Classroom in Australia (Doctoral dissertation), the University of Sydney.

Tamene, K. (2000). Classroom verbal behavior and learning opportunities in selected secondary school EFL classroom (Doctorial dissertation), Addis Ababa University, Ethiopia.

Ur, P. (1996). A course in language teaching. Cambridge: Cambridge University Press.

Ushioda, E. (1996). Developing a dynamic concept of L2 motivation. In T. Hickey, \& J. Williams (Eds.), Language, education and society in a changing world (pp. 239- 245). Clevedon: Multilingual Matters.

Ushioda, E. (2005), Language learning motivation: Current insights and implications. BATJ Journal, 6, 57-63.

Williams, M., \& Burden, R. (1997). Psychology for language teachers. Cambridge: Cambridge University Press. 
Mekuria, Z. B. 